\title{
Article \\ AI Recommendation Service Acceptance: Assessing the Effects of Perceived Empathy and Need for Cognition
}

\author{
Namhee Yoon ${ }^{1}$ and Ha-Kyung Lee ${ }^{2, *(1)}$ \\ 1 Human Ecology Research Center, Korea University, 145 Anam-ro, Seong-buk-gu, Seoul 02841, Korea; \\ v7nami@gmail.com \\ 2 Department of Textiles, Merchandising and Fashion Design, Seoul National University, Building 222, \\ 1 Gwanak-ro, Gwanak-gu, Seoul 08826, Korea \\ * Correspondence: agape@snu.ac.kr
}

Citation: Yoon, N.; Lee, H.K. AI Recommendation Service Acceptance: Assessing the Effects of Perceived Empathy and Need for Cognition. J Theor. Appl. Electron. Commer. Res. 2021, 16, 1912-1928. https://doi.org/ $10.3390 /$ jtaer16050107

Academic Editors: Gisela Ammetller and Eduardo Álvarez-Miranda

Received: 26 February 2021

Accepted: 10 June 2021

Published: 18 June 2021

Publisher's Note: MDPI stays neutral with regard to jurisdictional claims in published maps and institutional affiliations.

Copyright: (c) 2021 by the authors. Licensee MDPI, Basel, Switzerland. This article is an open access article distributed under the terms and conditions of the Creative Commons Attribution (CC BY) license (https:// creativecommons.org/licenses/by/ $4.0 /)$.

\begin{abstract}
This study investigated the effect of perceived technology quality and personalization quality on behavioral intentions, mediated by perceived empathy in using an artificial intelligence (AI) recommendation service. The study was based on a theoretical model of artificial intelligent device use acceptance. We also tested the moderating effect of individuals' need for cognition, influencing empathy. Data collection was conducted through an online survey using a nationally recognized consumer research panel service in Korea. The participants were asked to respond to their preferences and needs on sneakers; then, they randomly experienced the AI (versus human expert) recommendation service that offers a recommended product. A total of 200 data were analyzed using SPSS 21.0 for descriptive statistics, reliability analysis, and PROCESS analysis, and AMOS 21.0 for confirmatory factor analysis and structural equation modeling (SEM). Results revealed that, compared with the human (expert) recommendation service, the AI recommendation service increased perceived technology quality, which increased personalization quality. Technology and personalization quality had a positive influence on behavioral intentions, mediated by perceived empathy. In addition, when individuals had a high level of need for cognition, the effect of personalization quality on empathy was stronger. However, individuals with a low level of need for cognition perceived greater empathy, as technology quality increased. The findings of the current study improve understanding of how consumers accept AI technology-driven services in the online shopping context.
\end{abstract}

Keywords: AI recommendation service; technology quality; personalization quality; empathy; behavioral intentions; need for cognition

\section{Introduction}

Consumers enjoy the process of searching for optimal alternatives by exploring and comparing products through diverse information channels [1]. However, finding a suitable product is not a simple task for consumers because of the increasing number of online retailers and the diversity of online products. The recommendation service offered by an online retailer reduces consumers' efforts to search online and improves their shopping experiences despite the overwhelming amount of product information. Nowadays, rapid advances in computer technology have allowed retailers to use artificial intelligence (AI) for product recommendation services based on the analysis of consumer behavior data, such as search and purchase history, and preference. Amazon (http:/ / amazon.com, accessed on 10 June 2021), for example, uses an AI recommendation service that analyzes consumers' purchasing history to identify their preferences and interests. When customers access the website, they automatically receive an e-mail with a list of products that are personalized to their needs and meet their personal preferences [2,3]. Prior to these AI-based recommendation services, most professional recommendations were generally offered by human experts. In several industries (e.g., fashion, beauty, health), where professional information is essential for product/content recommendation, data for offering recommendation 
services have been collected based on experts' experience and knowledge [4]. Although human experts can make personalized recommendations to consumers based on their professional knowledge, AI-based recommendation services can offer a more consistent and accurate service compared with human employees due to its analytical abilities of considerable consumption data and high processing speeds $[5,6]$.

The majority of previous research on AI recommendation services focused on how recommendation services are established from a system operation perspective. Examples include how information filtering is structured or which types of filtering systems are utilized in the field [7-10] and which recommendation algorithms can effectively improve recommendation quality [9-11]. Several scholars have focused on consumer-related issues, such as the comparison of AI versus human expert recommendation services [12-14] and consumer acceptance of AI devices in service encounters [6], especially using the technology acceptance model (TAM) $[15,16]$. However, research on AI recommendation services from a consumer perspective is still limited because the literature does not explore consumers' psychological mechanism of how and why individuals accept AI recommendation services. According to the Computers Are Social Actors (CASA) paradigm, people tend to apply social rules of human-human interaction when they communicate or interact with computers [17]. Similar to this, although AI (intelligence demonstrated by a machine) is different from other technology-driven services, in terms of its human-like characteristics, research considering the context of AI characteristics is rarely conducted. Gursoy et al. [6] developed and tested a theoretical model of artificially intelligent device use acceptance (AIDUA) that can understand consumers' willingness to AIDUA. This proposed model includes three acceptance process stages, namely (1) the primary appraisal stage, (2) secondary appraisal stage, and (3) outcome stage [6]. We applied these three steps of acceptance generation for the research model used in the current study to explore the psychological mechanism of consumers for AI service acceptance and consider the context of unique AI characteristics.

This study aims to explore how consumers accept AI recommendation services, considering their cognitive assessment and emotional reaction, through a theoretical model of AIDUA. For cognitive evaluation toward AI recommendation services, we suggest technology quality and personalization quality. Although technology quality is a just tool for consumers to use the AI recommendation service efficiently (regarded as a peripheral factor), personalization quality is essential for the AI recommendation service acceptance (regarded as a central factor). The reason is that personalization quality is related to message content or issue-relevant thinking in service delivery. We will identify the role of technology and personalization quality in inducing empathy perception and also explore the interplay effects of two quality factors and individuals' need for cognition based on the elaboration likelihood model (ELM). In particular, the current study focuses on the mediating role of perceived empathy, which refers to consumers' perception of how AI service provides recommended products or content that meet their preferences and needs based on empathy toward customers [18,19]. In the context of service literature, empathy has been regarded as one of the five dimensions measuring service quality [20]. Empathetic services deliver social signals through which the service can respond to consumers who are in need [21]. Perceived empathy can also reflect how people interact with human-like intelligence in an AI-based online shopping environment [18]. Given that AI is empowered by human-like intelligence, testing the role of empathy, which is one of the common emotional characteristics of human beings, presents a theoretical implication by expanding the role of AI systems from an automated agent to an interactive companion. The current study's application of AIDUA can contribute to extensive literature on AI-based service acceptance by testing consumers' psychological mechanisms, such as cognitive assessment and emotional reaction. Consequently, our understanding of consumer behaviors in the AI-driven era can be enriched. 


\section{Theoretical Background}

\subsection{AI Recommendation Services}

Recommendations are information that consumers can refer to when making decisions and are regarded as an effective way for consumers to avoid information overload [22]. In the retail industry, most service or product recommendations were typically provided by human experts in a specific field (e.g., designer, cook, trainers) [12]. However, nowadays, with the development of computer science empowered by AI technology, an online retailer provides AI-based recommendation services that present customized products and content to individuals based on their past preferences or experiences [23,24].

Generally, recommendation services can be classified into three types based on how the recommendation is created through different systems and how appropriate items are filtered: (1) content-based, (2) user-based collaborative, and (3) knowledge-based filtering recommendation systems [8-10,25]. A content-based recommendation system matches the attributes of a user profile, wherein data on a user's tastes and preferences are stored with the attributes of a content option to recommend suitable new items to the user [8]. Therefore, this type of recommendation system recommends content or products similar to those searched, liked, or purchased by a user [9]. Then, a user-based collaborative filtering recommendation system identifies other customers whose preferences and tastes are similar to those of a user and recommends items that they (other users) have searched, liked, or purchased [8]. Finally, a knowledge-based filtering recommendation system uses recommendations of experts in a product category [10,25]. Moreover, such a system may be appropriate for popular products, such as fashion and design products, because they are easily influenced by trends. The current study focuses on AI technology-based recommendation services, which is a content-based recommendation system that recommends personalized content or products by matching users' tastes and preferences. We will explore consumers' perception and psychological mechanisms on how consumers accept AI recommendation services compared with human expert (non-AI) recommendation services, adopting a theoretical model of AIDUA.

\subsection{AIDUA Model}

Gursoy et al. [6] suggested a theoretical model of AIDUA to explain consumers' willingness to accept AI device use in service encounters. AIDUA incorporated a threestage process of AI device usage acceptance; that is, primary appraisal, secondary appraisal, and outcome stages [6]. In the primary appraisal stage, consumers assess the relevance and importance of using an AI device during the service delivery process by interacting with the device (for example, social influence, hedonic value, and anthropomorphism [6]). In the secondary appraisal stage, consumers activate a deliberate appraisal of benefits and costs, and perceive utilization of using an AI device (for example, performance expectancy and perceived effort expectancy [6]). This case can generate emotions toward the AI device $[6,26]$. In the outcome stage, consumers' emotions toward AI devices lead to their behavioral intentions.

The context of the current study focusing on AI recommendation services is somewhat different from that of the previous study proposing AIDUA [6]. The AI technology of the recommendation services used in the current study is invisibly embodied in the service rather than visibly presented as a form of a device or robot. Thus, consumers do not have the chance to interact with the AI device (e.g., talk or communicate with an AI chatbot) during the service delivery process. This case indicates that identifying consumers' responses toward recommended products is a key for understanding the AI recommendation service acceptance, rather than exploring how consumers interact with an AI device in the service delivery process. Therefore, we focus on exploring consumers' perception regarding the recommended results in the secondary appraisal, rather than consumers' response in the delivery process in the primary appraisal stage of AIDUA.

In this regard, we compare the AI and non-AI (human expert) recommendation services in the primary appraisal stage, where consumers first evaluate the relevance 
and congruence of AI devices to themselves [6,26]. Relevance is the degree to which the stimulus is related to the individuals [6]. Thus, relevant stimuli (i.e., recommended results by AI technology versus human experts) will cause further assessment and emotion during the secondary appraisal stage. Individuals' evaluation and emotions will defer depending on the types of recommendation source (i.e., AI intelligence versus human expert) [12-14]. In the context of AI service acceptance, consumers will evaluate its costs and benefits based on perceived performance and expectation [15] and then form the emotions toward AI service usage. The current study proposes technology quality and personalization quality as variables to explore individuals' perceived performance of AI service and empathy as an emotion variable. Technology quality and personalization quality will increase empathy. After the secondary appraisal process, empathy will have a positive effect on behavioral intentions.

\subsubsection{Technology Quality}

The majority of previous studies on consumers' technology acceptance have focused on perceived usefulness and perceived ease of use of technology to explore how consumers accept technology-driven services or products [27-29]. The perceived ease of use refers to the degree to which individuals believe that using a certain technology would be free of effort $[16,30,31]$. Then, perceived usefulness is defined as the degree to which individuals believe that using a certain technology would enhance their job performance $[16,30,31]$. Previous studies demonstrated the important role of perceived technology to accept the technology-driven services/products $[27,28]$. That is, useful and easily understood information of the services/product can reduce asymmetric information, process information behavior, and increase the degree of online trust [28,29].

However, in the context of AI recommendation services, AI services are similar to human-like intelligence empowered by AI technology [12]. Therefore, service users do not need to learn how to utilize AI services. Moreover, perceived ease of use, which was regarded as a core variable of the technology acceptance model $[16,30,31]$, can be irrelevant to the consumers' acceptant of AI service [6,7]. In addition, AI service generally acts similar to a regular salesperson interacting with consumers. Thus, the variable of perceived usefulness is also irrelevant to the consumers' acceptant of the AI service [6,7]. In this regard, the current study will focus on the degree to which individuals believe that certain technology is professional, excellent, and trustworthy, namely, technology quality. As the core value of the AI recommendation service is accurate personalization features [5], consumers' perception of how qualified technology is applied in the service will matter for their technology acceptance. In particular, consumers using AI recommendation services will perceive greater technology quality compared with human expert (non$\mathrm{AI}$ ) recommendation services. The reason is that the AI recommendation services are empowered by machine learning and computer vision technologies [12], whereas human expert recommendation is based on expert's personal knowledge and experience. Thereby we hypothesized the following:

Hypothesis 1 (H1). Consumers who use AI recommendation services (versus non-AI recommendation services) perceive greater technology quality.

\subsubsection{Personalization Quality}

Personalization refers to the ability to provide services or content based on individuals' preferences and consumption patterns [32]. The personalization service allows consumers to quickly and accurately find the information they want by selecting information that meets the needs and interests of the consumers [33]. With the rapid developments of AI demonstrated by machines, AI technology can provide personalized product or service recommendations by investigating past consumption experiences and preferences of consumers $[23,34]$. The current study defined personalization quality as the extent to 
which individuals perceive that content or a product, which the recommendation source recommends, reflects their experiences or tastes.

In the context of personalized recommendation services, recommendations from human experts are regarded as one of the reliable means of recommendation [35] because they are experienced and trained [12]. However, with the development of computer technology, AI can also offer a high level of personalized recommendations in a manner similar to human experts [23,34]. Several previous studies explored the effectiveness of the recommendations by $\mathrm{AI}$ and revealed that AI-based recommendations can sometimes achieve better evaluations than recommendations by human experts [12,14,36]. According to the machine heuristic, machines such as the AI system are unbiased and objective compared to humans [37], a difference that may allow AI to exert greater effectiveness in performing a task. Araujo et al. [36] empirically tested that automated decision making by $\mathrm{AI}$ in terms of recommendations was evaluated similarly or even better compared to a human agency for usefulness, fairness, and risk of decisions. This finding is in line with previous research on algorithmic appreciation, which indicated that people appreciate algorithmic recommendations against recommendations from a human agency (e.g., peers or professionals) [13,38]. Thurman et al. [38] also showed that individuals perceive algorithmic selection by AI based on the past consumption behavior of users to be a better way to get news compared with editorial curation by human experts. In this regard, individuals are likely to consider recommendations determined by AI to be more personalized than those by human experts, because personalization quality is dependent on how relevant and accurate content can be offered to users through appropriate and objective data analysis [32,39].

Hypothesis 2 (H2). Consumers who use AI recommendation services (versus non-AI recommendation services) perceive greater personalization quality.

Personalized recommendation includes the process of understanding consumers through profile building and delivering personalized content/products based on the knowledge about the content/products and the consumer [32,39]. Moreover, which kinds of recommendation algorithms were used is the key to improve the accuracy of personalized recommendation $[24,32,40,41]$. Automated recommendation or decision-making systems driven by AI can also be perceived as being unbiased and objective if its users perceive it as a machine that takes decisions because of the rule of the machine heuristic [36,37]. In other words, recommendations determined by a machine or an AI system embodied by a high level of technology may be perceived as a more accurate decision [36]. As service users cannot figure the types of recommendation algorithms or related technology, they might perceive the personalization quality of recommendation services depending on the technology quality they perceive holistically. If more users perceive that the technology for a personalized recommendation service is excellent and trustworthy, then they more likely perceive that the personalized content or products fit their personal preferences and tastes. We hypothesized the following:

Hypothesis 3 (H3). Perceived technology quality increases perceived personalization quality.

\subsubsection{Empathy}

Empathy is defined as the process of noticing, comprehending, and reacting to the emotional expressions of others [18] or the reactions of one individual to the observed experiences of another [19]. Empathy includes cognitive and affective aspects. Cognitive empathy allows individuals to understand the roles or perspectives of others [42], which is referred to as mind reading [43] or perspective-taking [44]. Affective empathy describes an emotional reaction that enables the understanding of others' feelings or affective status $[20,44]$. In the context of service literature on consumers' perception of service quality, empathy is identified as one factor of the five service quality dimensions [20]. Empathetic 
service delivers social signals through which the service can take the perspective of consumers and respond to those who are in need or distress [21]. In particular, empathy is a tool for effective human interaction in an AI-based online shopping environment [18] because AI-based services empowered by AI technology embody human-like intelligence in interacting with consumers [6,7].

According to a theoretical model of AIDUA, we expected that technology quality and personalization quality, as an assessment toward AI recommendation service, would influence empathy. Bove [20] also addressed that technology used in the context of service can facilitate the skill and ability to detect consumers' needs and wants, thereby increasing the empathy that consumers perceive. Moreover, Gorry and Westbrook [45] explored that consumers' emotional state in the real world on an online platform can be detected using software (i.e., technology) that analyzes language, speech, patterns, and tones. Thus, we hypothesized the following:

\section{Hypothesis 4 (H4). Perceived technology quality increases empathy.}

Moreover, another way of eliciting empathy is through the perception of attachmentrelated cues, such as kinship, friendship, familiarity, and similarity [46]. These relational cues may also be driven by interdependence (i.e., the extent to which the individual is reliant on the target) [44,47], leading to perspective taking and empathy [47]. In the context of AI recommendation services, personalization quality is evaluated depending on consumers personal information, such as their tastes, preferences, and consumption experience. This kind of personal information is usually only disclosed to people with sharing kinship, friendship, or familiarity. Thus, if consumers perceive that the recommendation service offers personalized content/products, then they perceive that the recommendation service empathizes with them. We hypothesized the following:

Hypothesis 5 (H5). Perceived personalization quality increases empathy.

\subsubsection{Behavioral Intentions}

In the outcome stage of the AIDUA model, emotion toward AI services consequently increases consumers' willingness to use these services in future service encounters [6]. In addition, as a factor evaluating service quality in the SERVQUAL literature, empathy leads to positive service quality perception [21], thereby leading to several positive outcomes, such as increased profitability [48], sales performance [49,50], and service satisfaction [51,52]. Thus, we expected that consumers' behavioral intention toward the recommendation service would increase, as they perceive the recommendation service as empathetic.

Although the AIDUA model did not expect the direct effect of service assessment on an outcome variable [6], on the basis of the findings of previous research $[27,53,54]$, we expect that technology quality and personalization quality are likely to increase behavioral intentions toward recommendation services. Ha and Stoel [53] suggested that perceived technology is a major determinant in determining online purchase intention. Then, Gefen et al. [27] argued that perceived technology has a direct impact on online purchase intention. Thus, we expected the direct effect of technology quality perception on behavioral intentions.

Regarding the effect of personalization quality, Tam and Ho [54] found that the level of preference matching, which is the level at which personalized content related to one's specific experience or taste is provided, influences consumers' acceptance of a personalized offer. When personalization quality is highly evaluated, people may perceive a high level of information reliability, value, and persuasiveness, which induces behavioral intentions. Thus, we hypothesized the following:

Hypothesis 6 (H6). Empathy increases behavioral intentions. 
Hypothesis 7 (H7). Perceived technology quality increases behavioral intentions.

Hypothesis 8 (H8). Perceived personalization quality increases behavioral intentions.

\subsection{Moderating Role of Need for Cognition}

Cacioppo and Petty [55] defined the need for cognition as the inner pleasure created by an individual's effort to process information. The need for cognition relates to an individual's tendency to engage in and enjoy effortful cognitive endeavors and reflects differences in information-processing motivations $[55,56]$. People with a low level of need for cognition tend to avoid effortful cognitive work and may rely on other experts' opinions in the face of complicated issues [56]. They also tend to depend on simple cues, such as source attraction and physical features [57]. By contrast, people with a high level of need for cognition intrinsically enjoy thinking and tend to exert more cognitive effort in evaluating messages because they have more cognitive resources available [56,57].

According to ELM, people can have two different levels of elaborative processing in response to persuasive messages [58], namely, central and peripheral routes. These two stages of information processing depend on the level of need for cognition [56,58-60]. For instance, those with a high need for cognition may focus on elaborating issue-relevant thinking (via central route) to process messages, whereas others with a low need for cognition can use simple cues to respond to these messages (via peripheral route) $[57,58]$. In the central route, central variables influencing consumer persuasion are related to the argument quality of a message [57-60]. The argument quality refers to the persuasive strength of arguments embedded in a message and reflects the reliability, persuasiveness, and value of information [61]. Then, in the peripheral route, peripheral cues affecting consumer persuasion are associated with the source credibility of a message rather than its content. Source credibility reflects diverse dimensions, such as the source's expertise, reputation, and site appearance [61].

Applying the context of the AI recommendation service, individuals with a higher need for cognition are likely to focus on personalization quality as a central variable (for the central route) because the argument quality of a message in the AI recommendation service is associated with the perception of whether a specific product or service is provided in line with personal needs [54]. If a recommended product matches consumers' needs and preferences, then they are likely to be persuaded to accept such a product and perceive that the AI recommendation service is empathetic. Thus, if consumers have a high need for cognition, then the effect of personalization quality on perceived empathy might be stronger; that is, through the central route. From a different perspective, individuals with a lower need for cognition are likely to focus on technology quality as a peripheral variable (for the peripheral route) because technology is a just tool for helping consumers to use the AI recommendation service more efficiently, irrelevant with the service content. Therefore, if consumers have a low need for cognition, the effect of technology quality on perceived empathy might be stronger; that is, through the peripheral route. From the above discussion, we proposed the following hypothesis, and Figure 1 shows the research model.

Hypothesis 9 (H9). For an individual with a lower need for cognition, the effect of technology quality (versus personalization quality) on empathy is stronger.

Hypothesis 10 (H10). For an individual with a higher need for cognition, the effect of personalization quality (versus technology quality) on empathy is stronger. 


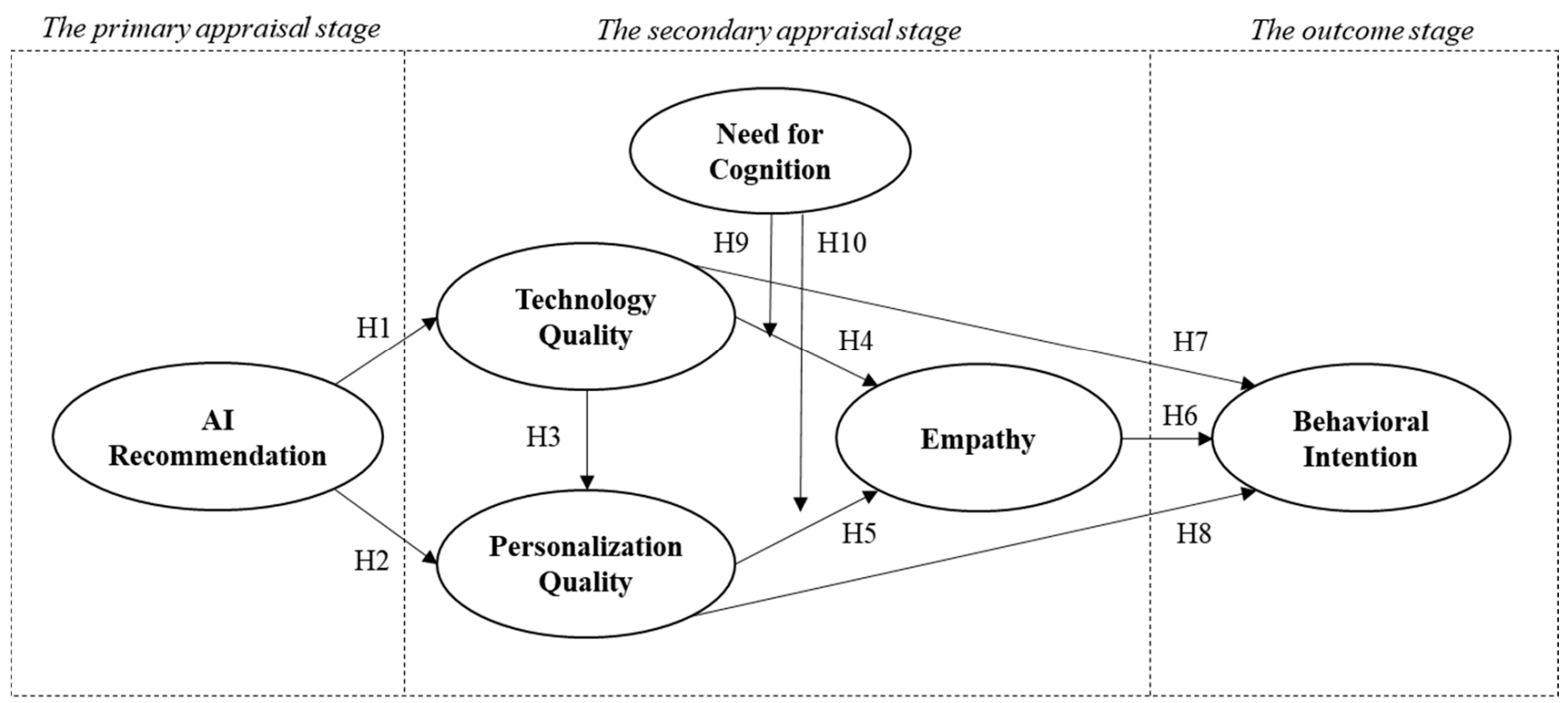

Figure 1. Research Model.

\section{Methodology}

\subsection{Stimuli and Procedure}

The AI recommendation service is generally distinct in terms of applying personal preference information to the logic of personalized recommendation from non-AI recommendations. Thus, AI recommendation services offer a self-relevant recommendation to consumers $[8,23,34]$, whereas the non-AI recommendation system may provide irrelevant information to consumers' tastes. The type of recommendations was manipulated using the scenarios. For the AI recommendation service, the phrase "these sneakers are recommended based on personal taste" was included on the recommendation page. This phrase was created based on examples of webpage presenting products/content recommended by AI. In the AI recommendation service that is actually in use, the term "personalization" or "personalized products/content" is usually highlighted on the webpage. Moreover, although the webpage does not specify that AI technology is used, consumers are implicitly aware of it. For non-AI recommendation services, the recommendation was based on an expert who was defined as an anonymous person (i.e., fashion buyer). The phrase "these sneakers are recommended by an expert (i.e., fashion buyer)" was included in the recommendation scenario.

The webpage of an AI online recommendation website as stimuli was designed. The Converse website (converse.co.kr) was adopted as the website image for manipulation of the scenario of a shoe (specifically, sneakers) recommendation service. The products (six sneakers), which were the stimuli, were recommended and presented to participants under the same condition.

Participants were randomly assigned to one of the two scenarios. Before the website stimuli were shown, the following procedure was conducted for all respondents. First, a scenario of visiting an online store to shop for sneakers was presented. Second, respondents were asked to provide their shoe size, foot shape, and preferred type and color of sneakers to obtain their personal information for the personalized recommendation service. Finally, respondents were exposed to one of the stimuli and were asked to answer online survey questions. The respondents allocated to the AI recommendation scenario were informed that the website recommended products based on personal information.

\subsection{Measurement}

Technology quality was measured in three items using Ali [62] and Yoo et al.'s [63] scale. Following Tam and Ho [54], personalization quality was measured by using two items. The measurement of empathy was based on Parasuraman et al.'s [64] scale as the 
component of SERVQUAL. Cognitive empathy to understand customers and the emphatic concern as an emotional response were measured in three items. The measurement of behavioral intention as online recommendation service usage intention was adopted from Mukherjee and Nath [65], including word of mouth, continued interaction with others, and continuous use intention of the recommendation service. Moreover, the need for cognition was defined as a consumer's tendency to engage in and enjoy cognitive activity following the previous studies $[55,56]$, which was measured in six items using Cacioppo and Petty's [55] scale. All continuous measurement items were measured using a sevenpoint Likert scale.

\subsection{Data Collection and Sample}

Data collection was conducted through an online survey using a nationally recognized consumer research panel service in Korea. Owing to the evaluation of an AI recommendation service as an online innovative service, purposive sampling was conducted for young consumers. Previous studies focusing on technology acceptance in terms of demographic distribution suggested that young online panels are appropriate for sampling $[6,66,67]$. Female and male consumers aged between 20 and 49 who had online shopping experience were invited to participate in the study. Considering the nature of the experimental stimuli, consumers who had no experience wearing sneakers normally were excluded, and screened samples were randomly allocated to one of the stimuli settings.

A total of 200 responses were collected. The sample consisted of 125 female $(62.5 \%)$ and 75 male (37.5\%) consumers. Respondents were in their $20 \mathrm{~s}(34.5 \%)$, 30s (31.5\%), and $40 \mathrm{~s}$ $(34.0 \%)$. Moreover, $82.5 \%$ of the sample had a college education, $62.5 \%$ were employed, and $6.5 \%$ were students. To examine the subjects' usual online shopping behaviors, their daily online browsing time and the amount of their monthly online purchase of fashion products were measured. The online fashion shopping behavior of respondents was compared between two scenarios (AI versus non-AI recommendation). No significant differences in online browsing time per day $(t=1.303, p=0.194)$ and monthly online expenditure of fashion products $(t=1.458, p=0.146)$ were observed.

\section{Results}

\subsection{Measurement Validity and Reliability}

To test the validity and reliability of the measurement, confirmatory factor analysis was conducted using AMOS 21.0. The results indicated an acceptable fit with the data $\left(\chi^{2}=65.012, d f=38\right.$, normed $\left.\chi^{2}=1.711\right)$. As goodness of fit indices, goodness of fit index $(\mathrm{GFI})=0.942$ and comparative fit index $(\mathrm{CFI})=0.983$ were above 0.9 , and root mean square residual $(R M R)=0.042$, root mean square error of approximation $($ RMSEA $)=0.060$ were less than 0.8 [68] (Table 1). All factor loadings were statistically significant at $p<0.001$. The average variance extracted (AVE) for the four constructs ranged from 0.653 to 0.836 , which exceeded 0.5 [69] and the composite reliability (CR) for the constructs was higher than 0.8 , indicating satisfactory convergent validity. Cronbach's alpha, which exceeded to the marginal value of 0.7 [70], indicated satisfactory internal consistency for all constructs.

To test discriminant validity, values for AVE and the squared correlation of constructs were compared for each pair of constructs (Table 2). All squared correlations were lower than the corresponding AVEs [71]; thus, the discriminant validity of the constructs was satisfactory.

\subsection{Hypothesis Test}

SEM was conducted using AMOS 21.0 to test the hypotheses. To test the model, recommendation as a latent variable was coded as one for AI recommendation and zero for non-AI recommendation. The structural model fit was satisfied $\left(\chi^{2}=76.340(\mathrm{~d} f=47)\right.$, Normed $\chi^{2}=1.624, \mathrm{GFI}=0.938, \mathrm{CFI}=0.981, \mathrm{RMR}=0.040, \mathrm{RMSEA}=0.056$ ).

As shown in Figure 2, the result of the SEM analysis showed that AI recommendation had a significant influence on technology quality $(\beta=0.156, p<0.05)$, and technology quality had a significant effect on personalization quality $(\beta=0.620, p<0.001)$. The direct 
effect of AI recommendation on personalization quality was not statistically significant. Additionally, the Sobel test was conducted to test the mediation effect of technology quality between AI recommendation and personalization quality. The result confirmed the entire mediation effect of technology quality $(z=2.008, p<0.05)$. Thus, $\mathrm{H} 1$ and H3 were supported, but $\mathrm{H} 2$ was rejected.

Table 1. Measurement model.

\begin{tabular}{|c|c|c|c|c|}
\hline Scale & $\begin{array}{c}\text { Standard } \\
\text { Loading }(\lambda)\end{array}$ & $\begin{array}{l}\text { Cronbach's } \\
\alpha \alpha\end{array}$ & AVE & CR \\
\hline Technology quality & & \multirow{4}{*}{0.841} & \multirow{4}{*}{0.653} & \multirow{4}{*}{0.805} \\
\hline The recommendation service uses new technology & 0.850 & & & \\
\hline The recommendation service uses professional technology & 0.830 & & & \\
\hline The recommendation service uses a high level of technology & 0.739 & & & \\
\hline \multicolumn{2}{|l|}{ Personalization quality } & \multirow{3}{*}{0.910} & \multirow{3}{*}{0.836} & \multirow{3}{*}{0.854} \\
\hline $\begin{array}{l}\text { The recommendation service considers the products that } \\
\text { match my needs. }\end{array}$ & 0.922 & & & \\
\hline The recommendation service is personalized to me. & 0.907 & & & \\
\hline \multicolumn{2}{|l|}{ Empathy } & \multirow{4}{*}{0.899} & \multirow{4}{*}{0.754} & \multirow{4}{*}{0.871} \\
\hline The recommendation service understands my specific needs. & 0.896 & & & \\
\hline The recommendation service reflects my interests at heart. & 0.894 & & & \\
\hline The recommendation service gives me individual attention. & 0.812 & & & \\
\hline \multicolumn{2}{|l|}{ Behavioral intention } & \multirow{4}{*}{0.871} & \multirow{4}{*}{0.694} & \multirow{4}{*}{0.829} \\
\hline $\begin{array}{l}\text { I would like to recommend online recommendation services } \\
\text { to others. }\end{array}$ & 0.873 & & & \\
\hline $\begin{array}{l}\text { I would like to discuss with others about online } \\
\text { recommendation services. }\end{array}$ & 0.837 & & & \\
\hline $\begin{array}{l}\text { I am willing to use online recommendation services to search } \\
\text { for products. }\end{array}$ & 0.787 & & & \\
\hline
\end{tabular}

Notes: All $\lambda$ were statistically significant at $p<0.001, \chi^{2}=65.012(d f=38)$, Normed $\chi^{2}=1.711, \mathrm{GFI}=0.942, \mathrm{CFI}=0.983, \mathrm{RMR}=0.042$, RMSEA $=0.060$.

Table 2. AVE, squared correlation coefficient.

\begin{tabular}{ccccc}
\hline & Technology Quality & $\begin{array}{c}\text { Personalization } \\
\text { Quality }\end{array}$ & Empathy & $\begin{array}{c}\text { Behavioral } \\
\text { Intention }\end{array}$ \\
\hline Technology quality & $0.653^{\mathrm{a}}$ & & & \\
Personalization quality & $0.396^{\mathrm{b}}$ & 0.836 & 0.754 & 0.602 \\
Empathy & 0.624 & 0.472 & 0.694 \\
Behavioral intention & 0.536 & 0.255 & 0.602 \\
\hline
\end{tabular}

Notes: ${ }^{\mathrm{a}}$-Values at diagonal (italics) represent AVE of the construct; ${ }^{\mathrm{b}}$ - Lower values in the matrix represent the squared correlation coefficient between constructs.

Technology quality $(\beta=0.594, p<0.001)$ and personalization quality $(\beta=0.313$, $p<0.001$ ) had significant effects on empathy, and the effect of empathy on behavioral intention was statistically significant $(\beta=0.572, p<0.001)$. H4, H5, and H6 were supported. Technology quality had a direct effect on behavioral intention $(\beta=0.355, p<0.001)$, but personalization did not directly influence behavioral intention. H7 was supported, but H8 was rejected. The Sobel test confirmed the mediation effect of empathy between technology quality and behavioral intention $(\mathrm{z}=2.847, p<0.01)$ and between personalization quality and behavioral intention $(\mathrm{z}=3.133, p<0.01)$. The mediation analysis implied that empathy partially mediated the relationship between technology quality and behavioral intention and fully mediated that between personalization quality and behavioral intention. 


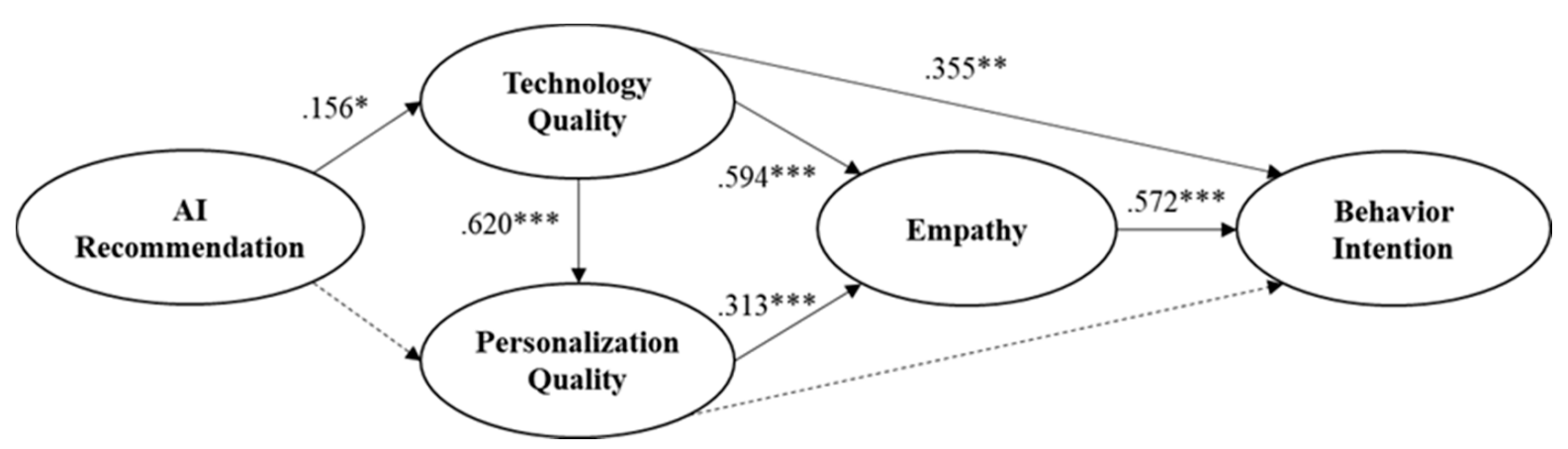

Figure 2. Structure model. $(* * * * * * *$ indicate the remainder digits).

The results imply that consumers using AI recommendation services perceive greater technology quality than those who use non-AI recommendation services. In addition, AI service users consequently perceive the personalization quality of a recommendation service depending on technology quality. The personalization quality of the AI service encompasses with the evaluation of AI technology. Thus, the personalization process and outcome quality are evaluated first regarding whether the online recommendation service reflects a consumer's own needs by AI technology. In this case, attitude toward the online recommendation service will be determined. Advances in AI technology will influence retailers to offer personalization services for their consumers and encourage AI service users to form strong behavioral intentions.

The current study also found that the direct path between personalization quality and behavioral intention was not significant, and the mediating role of empathy was supported. In the AI recommendation service scape, perceived empathy reflects how users experience the human-like intelligence services [18]. Although AI recommendations provide highquality personalized services, acceptance of an AI recommendation service is encouraged when consumers perceive empathy with AI recommendation.

\subsection{Moderation Effect of Need for Cognition}

To test H9 and H10, we employed bias-corrected bootstrapping using Hayes' [72] PROCESS Macro Model 15 with 5000 samples. Need for cognition was predicted as the moderator between technology quality as the independent variable and empathy as the dependent variable (H9) and also between personalization quality as the mediating variable and empathy (H10).

The results revealed that interaction terms of technology quality and need for cognition had a negative effect on empathy $(b=-0.108, t=-2.651,95 \%$ CI $(-0.188,-0.027))$. In the case of a consumer with low need for cognition (Mean $-1 \mathrm{SD}=3.276$ ), technology quality influenced stronger on empathy (Effect $=0.552,95 \%$ CI $(0.450,0.699)$; see Table 3) than in case of consumers with medium (Effect $=0.436,95 \% \mathrm{CI}(0.310,0.561)$ ) and high need for cognition (Effect $=0.320,95 \% \mathrm{CI}(0.162,0.478)$ ). To identify the ranges of need for the cognition level for which the effect of technology quality on empathy was significant, the Johnson-Neyman technique was used. The results revealed that technology quality influenced empathy when the need for the cognition value was less than $6.396\left(b_{\mathrm{JN}}=0.214, t=1.972,95 \% \mathrm{CI}(0.000,0.429)\right)$. The moderating effect of need for cognition between personalization quality and empathy was statistically significant $(b=0.083, t=2.162,95 \% \mathrm{CI}(0.007,0.159))$. Moreover, the effect was stronger when a consumer perceived a need for higher cognition (Table 3). According to the JohnsonNeyman analysis, the effects of personalization quality on empathy were significant when the value of the need for cognition was more than $2.397\left(b_{\mathrm{JN}}=0.159, t=1.972,95 \% \mathrm{CI}\right.$ $(0.000,0.318))$ In this regard, for an individual with a lower need for cognition, the effect of technology quality on empathy is stronger, but for a consumer with a high need for cognition, the effect of personalization quality on empathy is stronger. Thus, H9 and H10 were accepted (Table 4). 
Table 3. Conditional effect of technology quality on empathy at value of need for cognition.

\begin{tabular}{cccc}
\hline \multirow{2}{*}{ Value of Need for Cognition } & \multirow{2}{*}{ Effect } & \multicolumn{2}{c}{ 95\% Confidence Interval } \\
\cline { 3 - 4 } & & LLCI & ULCI \\
\hline Mean - 1 SD (3.276) & 0.552 & 0.405 & 0.699 \\
Mean (4.350) & 0.436 & 0.310 & 0.561 \\
Mean + 1 SD (5.423) & 0.320 & 0.162 & 0.478 \\
\hline
\end{tabular}

Table 4. Conditional effect of personalization quality on empathy at value of need for cognition.

\begin{tabular}{cccc}
\hline \multirow{2}{*}{ Value of Need for Cognition } & Effect & \multicolumn{2}{c}{$\mathbf{9 5 \%}$ Confidence Interval } \\
\cline { 3 - 4 } & & LLCI & ULCI \\
\hline Mean - 1 SD (3.276) & 0.232 & 0.121 & 0.342 \\
Mean (4.350) & 0.321 & 0.230 & 0.413 \\
Mean + 1 SD (5.423) & 0.411 & 0.277 & 0.545 \\
\hline
\end{tabular}

The results imply that when consumers perceive a higher need for cognition, the effect of personalization quality through the AI recommendation service on empathy is stronger. This notion was supported by the ELM studies on online services [54,73]. According to previous studies about the role of need for cognition on consumers' evaluation $[56,59,60]$, consumers with a high need for cognition exert considerable cognitive effort into information processing and form attitudes based on personalization quality, which is key to AI recommendation services. All results of the study are shown in Table 5.

Table 5. Hypothesis test.

\begin{tabular}{ccc}
\hline & Hypothesis & Result \\
\hline H1 & AI recommendation $\rightarrow$ Technology quality & Supported \\
H2 & AI recommendation $\rightarrow$ Personalization quality & Rejected \\
H3 & Technology quality $\rightarrow$ Personalization quality & Supported \\
H4 & Technology quality $\rightarrow$ Empathy & Supported \\
H5 & Personalization quality $\rightarrow$ Empathy & Supported \\
H6 & Empathy $\rightarrow$ Behavioral intention & Supported \\
H7 & Technology quality $\rightarrow$ Behavioral intention & Supported \\
H8 & Personalization quality $\rightarrow$ Behavioral intention & Rejected \\
H9 & Moderating effect of need for cognition: & Supported \\
& Technology quality $\rightarrow$ Empathy & \\
H10 & Moderating effect of need for cognition: & Supported \\
& Personalization quality $\rightarrow$ Empathy & \\
\hline
\end{tabular}

\section{Conclusions}

\subsection{General Discussion}

This study explained how consumers evaluate AI recommendation services and accept this innovative service to use in their shopping. The results indicated that, first, technology quality is an important cue to evaluate the AI recommendation service. Consumers can consider AI recommendation as an innovative technology-driven service that provides personalized products matching with customer's preferences, although the AI service is not visibly presented during the service delivery process. Therefore, when consumers have an AI technology-embodied experience, their perceived quality about technology can directly drive a positive attitude and behavioral intention toward AI recommendation services. Moreover, personalization quality, which falls under the outcome of an AI recommendation, is affected by technology quality. The accuracy of personalization recommendation is the key for an AI service $[5,24,32,40,41]$. However, the results showed that, although AI recommendation offers a high level of personalization, empathic feeling such as human relationship is important to accept the AI recommendation service. In the 
context of a technology-driven service, the role of emotional factors, such as empathy, can be empathized on consumers' usage.

In addition, the influence of technology quality and personalization quality on empathy depends on consumers' need for cognition. When consumers have a high need for cognition, the mediating effect of personalization quality between technology quality and empathy is stronger. They tend to pursue a high level of interpretation by exerting considerable cognitive effort along with deep involvement [54,56,58-60]. Consumers with a high need for cognition can carefully evaluate the personalization quality based on their preferences and demands, and the highly personalized service can evoke empathy for AI recommendation services.

\subsection{Theoretical and Management Implications}

This study provides new insights into the consumers' acceptance of AI recommendation services. Most previous studies have evaluated AI recommendation services from the perspective of a system programmer or a retailer by investigating how information filtering is structured [7], including the recommendation algorithms that can effectively enhance recommendation quality [11]. Despite the prevalence of recommendation services in e-commerce, only few studies have explored online recommendation services from consumers' perspectives to explore consumers' perceptions and usage intention [2,3,74]. For example, Hsu et al. [2] explored the effect of different types of sentiment-related words on recommendations' words, and revealed that words, including strong sentiments, obtained more intentions than words with neutral sentiments. Heimbach et al. [3] found that consumers' Facebook profile data were an effective source for creating meaningful product recommendations, rather than random data from a product sales database. Despite that these previous studies identified the effective way of product recommendation, they failed to focus on the consumers' underlying mechanism on why and how consumers adopt services or products recommended by a retailer. In addition, Jiang et al. [74] focused on maximizing customer satisfaction through an online recommendation system by employing an innovative associative classification method. However, they also missed consumers psychological factors inducing satisfaction. We differentiate the study from the previous works on recommendation services by complementing the limitations of prior research and concentrating on the consumers' psychological mechanism.

Our findings have several theoretical contributions. First, the current study explained consumer acceptance of AI recommendation services based on the AIDUA model, which were rarely tested and achieved a satisfactory fit to data. Previous studies mainly depended on TAM to explain the innovative service acceptance of consumers [27-29]. As AI recommendation services offer embodied experience to consumers, the TAM model, exploring users' acceptance considering perceived technology (e.g., perceived ease of use, perceived usefulness), is not enough to demonstrate the consumers' experience while using AI-based services. Gursoy et al.'s [6] AIDUA model, including the three generation stages (the primary appraisal stage, assessment and emotion with AI service as the second appraisal stage, and the outcome stage), can explain the consumers' cognitive assessment and emotional reaction to AI services.

Second, the current study found the important role of empathy on AI service acceptance. Empathy is related to human interaction, such as comprehension, reaction, and mind-reading to others [18-20,42-44]. The early studies about SERVQUAL [64,75] identified empathy as one of the service quality dimensions. However, considering the servicescape, such as e-commerce adopting AI technology, this study verified that empathy mediated the relation between the personalization quality and behavior. In general, when consumers feel empathy for the service provider, they less perceive time and energy cost [52] and are more satisfied with the service [51]. Although AI recommendation is an innovative technology-driven service, the findings indicated that AI recommendation is important for the mediating effect of human-like factors between service assessment and behavioral intention in AI-based services. Studies relating to the embodied technology 
experience (e.g., VR tour, game, and shopping) revealed that the stimulated empathy by technology helps consumers feel realistic and have credibility in service [76,77]. In regard, a consumer can perceive empathy as an effective tool in online shopping services empowered by AI technology $[6,7,18]$.

Third, this study investigated which kinds of factors are influential for the AI service based on the level of the individuals' information elaboration processing. This study adopted the need for cognition, which is related to information-processing motivation [55] as consumers' inherent traits. The results show that the effect of personalization quality on empathy is stronger for consumers with a high need for cognition. Personalization quality is referred to as argument quality that is the central variable for self-relevant information processing [54,61]. Future studies can investigate the active usage of AI recommendation services by comparing the need for cognition with consumers' behavioral characteristics. Further research can consider user variables, such as curiosity and innovativeness, which have been discussed to influence the performance of technology-based services, thereby affecting the performance of AI recommendations.

This study was conducted using stimuli based on scenarios to discover the psychological mechanisms used for evaluating AI services. The study has limitations, in that the presence of personalized recommendation service situations in online shopping is assumed. This study was manipulated to obtain information on consumers' preferences based on product attributes. Subsequent research is required to re-examine the manipulation method of consumers' personalization, and this method may be tested on a website to effectively identify consumers' preferences. Future research may test which type of recommendation information enhances personalization quality.

This study also has a limitation in terms of generalizing the results because of convenience sampling. Both young females and males participated in the study. In terms of technology acceptance, consumer characteristics such as gender and age should be considered as influential factors that explain AI recommendation usage in future research.

Although the study used a cross-sectional design to investigate the acceptance of AI recommendation services, these services can be evaluated based on the experiences of consumers. Thus, future research is required to approach such topic via longitudinal studies. With the accumulated experiences of consumers with AI service, the effects of perceived AI service quality on their usage could change over time. Future research could measure the change in constructs over time while controlling for their covariance stability [78].

AI recommendation services are newly introduced services by an online retailer, and understanding who uses this service and why they use it is important. In this regard, the results provide insights into how online consumers accept AI recommendation services through the perceived quality, including empathy with AI services.

First, this study verified that, compared with non-AI recommendations, AI services can induce consumers' positive attitudes and behaviors through the quality evaluation of the AI recommendation process and outcome. Specifically, technology quality was influential to the personalization quality of AI services. Given the invisibility of AI recommendation processing for service delivery, consumers using the AI recommendation service infer it as an innovative technology-driven service. Moreover, consumers with a low need for cognition tend to minimize their effort in the information process to achieve behavioral intention based on the perception of AI technology quality. Markers should inform consumers that an AI recommendation service is based on innovative technology and provides a highly personalized quality service.

Personalization quality should be considered by online service providers. Personalized information is based on consumers' preferences and their past purchases. Forming initial trust in a new website is followed by argument quality [61], and the level of matching with consumers' preferences determines the personalization quality. When accessing a website, developing an interface that can obtain sufficient information on consumers' shopping preferences and, in the case of existing consumers, developing a good AI algorithm based on their online behavioral data is necessary. Previous studies suggested the 
congruence with self-concept, and others/brands influence the positive attitude to others/brands $[79,80]$. Online retailers emphasize relevance with consumers during delivering AI recommendation services.

In the context of AI recommendation services without support from empathic personnel, human-like interaction with technology is more emphasized. The empathy of the communication process can be more important than the result of interaction in the use of an AI service. Online retailers are required to offer an empathic service in tune with consumers' subtle preferences and develop the reaction tools for meeting customers' needs.

Author Contributions: Conceptualization, N.Y. and H.K.L.; literature review, H.K.L.; methodology and data analysis, N.Y.; writing-review and editing, N.Y. and H.K.L. All authors have read and agreed to the published version of the manuscript.

Funding: This research was supported by a Korea University Grant.

Institutional Review Board Statement: Ethical review and approval were waived for this study, due to the data being collected from online panels of a professional research company. Any personal data were excluded from the research.

Informed Consent Statement: Informed consent was obtained from all subjects involved in the study.

Data Availability Statement: The data presented in this study are available on request from the corresponding author.

Conflicts of Interest: The authors declare no conflict of interest.

\section{References}

1. Ewerhard, A.-C.; Sisovsky, K.; Johansson, U. Consumer decision-making of slow moving consumer goods in the age of multichannels. Int. Rev. Retail. Distrib. Consum. Res. 2019, 29, 1-22. [CrossRef]

2. Hsu, P.-Y.; Lei, H.-T.; Huang, S.-H.; Liao, T.H.; Lo, Y.-C.; Lo, C.-C. Effects of sentiment on recommendations in social network. Electron. Mark. 2019, 29, 253-262. [CrossRef]

3. Heimbach, I.; Gottschlich, J.; Hinz, O. The value of user's Facebook profile data for product recommendation generation. Electron. Mark. 2015, 25, 125-138. [CrossRef]

4. Yang, D.; Qu, B.; Cudré-Mauroux, P. Privacy-preserving social media data publishing for personalized ranking-based recommendation. IEEE Trans. Knowl. Data Eng. 2018, 31, 507-520. [CrossRef]

5. West, A.; Clifford, J.; Atkinson, D. "Alexa, build me a brand" An Investigation into the impact of Artificial Intelligence on Branding. Bus. Manag. Rev. 2018, 9, 321-330.

6. Gursoy, D.; Chi, O.H.; Lu, L.; Nunkoo, R. Consumers acceptance of artificially intelligent (AI) device use in service delivery. Int. J. Inf. Manag. 2019, 49, 157-169. [CrossRef]

7. Lu, L.; Cai, R.; Gursoy, D. Developing and validating a service robot integration willingness scale. Int. J. Hosp. Manag. 2019, 80, 36-51. [CrossRef]

8. Lops, P.; De Gemmis, M.; Semeraro, G. Content-based recommender systems: State of the art and trends. Recomm. Syst. Handb. 2011, 73-105. [CrossRef]

9. Pazzani, M.J.; Billsus, D. Content-based recommendation systems. In The Adaptive Web; Springer: Berlin/Heidelberg, Germany, 2007; pp. 325-341.

10. Felfernig, A.; Friedrich, G.; Jannach, D.; Zanker, M. An integrated environment for the development of knowledge-based recommender applications. Int. J. Electron. Commer. 2006, 11, 11-34. [CrossRef]

11. Xu, Y.; Yin, J.; Deng, S.; Xiong, N.N.; Huang, J. Context-aware QoS prediction for web service recommendation and selection. Expert Syst. Appl. 2016, 53, 75-86. [CrossRef]

12. Li, Z.; Rau, P.-L.P.; Huang, D. Who Should Provide Clothing Recommendation Services: Artificial Intelligence or Human Experts? J. Inf. Technol. Res. 2020, 13, 113-125. [CrossRef]

13. Logg, J.M.; Minson, J.A.; Moore, D.A. Algorithm appreciation: People prefer algorithmic to human judgment. Organ. Behav. Hum. Decis. Process. 2019, 151, 90-103. [CrossRef]

14. Wang, J.; Molina, M.D.; Sundar, S.S. When expert recommendation contradicts peer opinion: Relative social influence of valence, group identity and artificial intelligence. Comput. Hum. Behav. 2020, 107, 106278. [CrossRef]

15. Venkatesh, V.; Thong, J.Y.; Xu, X. Consumer acceptance and use of information technology: Extending the unified theory of acceptance and use of technology. MIS Q. 2012, 36, 157-178. [CrossRef]

16. McKechnie, S.; Winklhofer, H.; Ennew, C. Applying the technology acceptance model to the online retailing of financial services. Int. J. Retail. Distrib. Manag. 2006, 34, 388-410. [CrossRef]

17. Reeves, B.; Nass, C. The Media Equation: How People Treat Computers, Television, and New Media Like Real People; Cambridge University Press: Cambridge, UK, 1996. 
18. Adam, M.; Wessel, M.; Benlian, A. AI-based chatbots in customer service and their effects on user compliance. Electron. Mark. 2020, 1-19. [CrossRef]

19. Davis, M.H. Measuring individual differences in empathy: Evidence for a multidimensional approach. J. Personal. Soc. Psychol. 1983, 44, 113. [CrossRef]

20. Bove, L.L. Empathy for service: Benefits, unintended consequences, and future research agenda. J. Serv. Mark. 2019, 33, 31-43. [CrossRef]

21. Wieseke, J.; Geigenmüller, A.; Kraus, F. On the role of empathy in customer-employee interactions. J. Serv. Res. 2012, 15, 316-331. [CrossRef]

22. Aljukhadar, M.; Senecal, S.; Daoust, C.-E. Using recommendation agents to cope with information overload. Int. J. Electron. Commer. 2012, 17, 41-70. [CrossRef]

23. Wei, J.; He, J.; Chen, K.; Zhou, Y.; Tang, Z. Collaborative filtering and deep learning based recommendation system for cold start items. Expert Syst. Appl. 2017, 69, 29-39. [CrossRef]

24. Lee, W.P. Applying domain knowledge and social information to product analysis and recommendations: An agent-based decision support system. Expert Syst. 2004, 21, 138-148. [CrossRef]

25. Lee, D.; Kim, U.; Yeom, K. Content recommendation system using user context-aware based knowledge filtering in smart environments. J. Korean Inst. Next Gener. Comput. 2017, 13, 35-48.

26. Lazarus, R.S. Progress on a cognitive-motivational-relational theory of emotion. Am. Psychol. 1991, 46, 819. [CrossRef]

27. Gefen, D.; Karahanna, E.; Straub, D.W. Trust and TAM in online shopping: An integrated model. MIS Q. 2003, 27, 51-90. [CrossRef]

28. Koufaris, M.; Hampton-Sosa, W. The development of initial trust in an online company by new customers. Inf. Manag. 2004, 41, 377-397. [CrossRef]

29. Chen, Y.H.; Barnes, S. Initial trust and online buyer behaviour. Ind. Manag. Data Syst. 2007, 107, 21-36. [CrossRef]

30. Davis, F.D. Perceived usefulness, perceived ease of use, and user acceptance of information technology. MIS Q. 1989, 13, 319-340. [CrossRef]

31. Henderson, R.; Divett, M.J. Perceived usefulness, ease of use and electronic supermarket use. Int. J. Hum. Comput. Stud. 2003, 59, 383-395. [CrossRef]

32. Liang, T.-P.; Yang, Y.-F.; Chen, D.-N.; Ku, Y.-C. A semantic-expansion approach to personalized knowledge recommendation. Decis. Support Syst. 2008, 45, 401-412. [CrossRef]

33. Kim, H.; Jung, S.; Ryu, G. A Study on the Restaurant Recommendation Service App Based on AI Chatbot Using Personalization Information. Int. J. Adv. Cult. Technol. 2020, 8, 263-270.

34. Joly, A.; Goëau, H.; Botella, C.; Glotin, H.; Bonnet, P.; Vellinga, W.-P.; Planqué, R.; Müller, H. Overview of lifeclef 2018: A large-scale evaluation of species identification and recommendation algorithms in the era of ai. In International Conference of the Cross-Language Evaluation Forum for European Languages; Springer: Cham, Switzerland, 2018; pp. 247-266.

35. East, R.; Singh, J.; Wright, M.; Vanhuele, M. Consumer Behaviour: Applications in Marketing; Sage: New York, NY, USA, 2016.

36. Araujo, T.; Helberger, N.; Kruikemeier, S.; De Vreese, C.H. In AI we trust? Perceptions about automated decision-making by artificial intelligence. AI Soc. 2020, 35, 611-623. [CrossRef]

37. Sundar, S.S. The MAIN Model: A Heuristic Approach to Understanding Technology Effects on Credibility; MacArthur Foundation Digital Media and Learning Initiative, The MIT Press: Cambridge, MA, USA, 2008.

38. Thurman, N.; Moeller, J.; Helberger, N.; Trilling, D. My friends, editors, algorithms, and I: Examining audience attitudes to news selection. Digit. J. 2019, 7, 447-469. [CrossRef]

39. Adomavicius, G.; Tuzhilin, A. Personalization technologies: A process-oriented perspective. Commun. ACM 2005, 48, 83-90. [CrossRef]

40. Ahn, H.J. Utilizing popularity characteristics for product recommendation. Int. J. Electron. Commer. 2006, 11, 59-80. [CrossRef]

41. Cheung, K.-W.; Tsui, K.-C.; Liu, J. Extended latent class models for collaborative recommendation. IEEE Trans. Syst. Man Cybern. Part A 2004, 34, 143-148. [CrossRef]

42. Devoldre, I.; Davis, M.H.; Verhofstadt, L.L.; Buysse, A. Empathy and social support provision in couples: Social support and the need to study the underlying processes. J. Psychol. 2010, 144, 259-284. [CrossRef]

43. Baron-Cohen, S. Autism, hypersystemizing, and truth. Q. J. Exp. Psychol. 2008, 61, 64-75. [CrossRef] [PubMed]

44. Preston, S.D.; De Waal, F.B. Empathy: Its ultimate and proximate bases. Behav. Brain Sci. 2002, 25, 1-20. [CrossRef]

45. Gorry, G.A.; Westbrook, R.A. Once more, with feeling: Empathy and technology in customer care. Bus. Horiz. 2011, 54, 125-134. [CrossRef]

46. Cialdini, R.B.; Schaller, M.; Houlihan, D.; Arps, K.; Fultz, J.; Beaman, A.L. Empathy-based helping: Is it selflessly or selfishly motivated? J. Personal. Soc. Psychol. 1987, 52, 749. [CrossRef]

47. Batson, C.D.; Early, S.; Salvarani, G. Perspective taking: Imagining how another feels versus imaging how you would feel. Personal. Soc. Psychol. Bull. 1997, 23, 751-758. [CrossRef]

48. Ye, J.; Dong, B.; Lee, J.-Y. The long-term impact of service empathy and responsiveness on customer satisfaction and profitability: A longitudinal investigation in a healthcare context. Mark. Lett. 2017, 28, 551-564. [CrossRef]

49. Stock, R.M.; Hoyer, W.D. An attitude-behavior model of salespeople's customer orientation. J. Acad. Mark. Sci. 2005, 33, 536-552. [CrossRef] 
50. Drollinger, T.; Comer, L.B. Salesperson's listening ability as an antecedent to relationship selling. J. Bus. Ind. Mark. 2013, 28, 50-59. [CrossRef]

51. Davis, C.; Jiang, L.; Williams, P.; Drolet, A.; Gibbs, B.J. Predisposing customers to be more satisfied by inducing empathy in them. Cornell Hosp. Q. 2017, 58, 229-239. [CrossRef]

52. Berry, L.L.; Seiders, K.; Grewal, D. Understanding service convenience. J. Mark. 2002, 66, 1-17. [CrossRef]

53. Ha, S.; Stoel, L. Promoting customer-retailer relationship building: Influence of customer trustworthiness of customer loyalty programme marketing. J. Cust. Behav. 2008, 7, 215-229. [CrossRef]

54. Tam, K.Y.; Ho, S.Y. Web personalization as a persuasion strategy: An elaboration likelihood model perspective. Inf. Syst. Res. 2005, 16, 271-291. [CrossRef]

55. Cacioppo, J.T.; Petty, R.E. The need for cognition. J. Personal. Soc. Psychol. 1982, 42, 116. [CrossRef]

56. Lin, C.-L.; Lee, S.-H.; Horng, D.-J. The effects of online reviews on purchasing intention: The moderating role of need for cognition. Soc. Behav. Personal. 2011, 39, 71-81. [CrossRef]

57. Petty, R.E.; Cacioppo, J.T.; Goldman, R. Personal involvement as a determinant of argument-based persuasion. J. Personal. Soc. Psychol. 1981, 41, 847. [CrossRef]

58. Petty, R.E.; Cacioppo, J.T. The effects of involvement on responses to argument quantity and quality: Central and peripheral routes to persuasion. J. Personal. Soc. Psychol. 1984, 46, 69. [CrossRef]

59. Batra, R.; Stayman, D.M. The role of mood in advertising effectiveness. J. Consum. Res. 1990, 17, 203-214. [CrossRef]

60. Haugtvedt, C.P.; Petty, R.E.; Cacioppo, J.T. Need for cognition and advertising: Understanding the role of personality variables in consumer behavior. J. Consum. Psychol. 1992, 1, 239-260. [CrossRef]

61. Zhou, T.; Lu, Y.; Wang, B. Examining online consumers' initial trust building from an elaboration likelihood model perspective. Inf. Syst. Front. 2016, 18, 265-275. [CrossRef]

62. Ali, A. Pioneering versus incremental innovation: Review and research propositions. J. Prod. Innov. Manag. 1994, $11,46-61$. [CrossRef]

63. Yoo, J.M.; Kim, S.-H.; Yi, Y.J. Determinants of perceived innovativeness and their relationship with intention of product adoption: Focusing on consumers' perspectives. J. Korean Mark. Assoc. 2006, 21, 27-52.

64. Parasuraman, A.; Zeithaml, V.A.; Berry, L. SERVQUAL: A multiple-item scale for measuring consumer perceptions of service quality. J. Retail. 1988, 64, 12-40.

65. Mukherjee, A.; Nath, P. Role of electronic trust in online retailing: A re-examination of the commitment-trust theory. Eur. J. Mark. 2007, 41, 1173-1202. [CrossRef]

66. Poushneh, A.; Vasquez-Parraga, A.Z. Discernible impact of augmented reality on retail customer's experience, satisfaction and willingness to buy. J. Retail. Consum. Serv. 2017, 34, 229-234. [CrossRef]

67. Perry, A. Consumers' acceptance of smart virtual closets. J. Retail. Consum. Serv. 2016, 33, 171-177. [CrossRef]

68. Hair, J.F. Multivariate Data Analysis; Prentice Hall: Upper Saddle Rive, NJ, USA, 2009.

69. Bagozzi, R.P.; Yi, Y. On the evaluation of structural equation models. J. Acad. Mark. Sci. 1988, 16, 74-94. [CrossRef]

70. Nunnally, J.C. Psychometric Theory 3E; Tata McGraw-Hill Education: New York, NY, USA, 1994.

71. Fornell, C.; Larcker, D.F. Evaluating structural equation models with unobservable variables and measurement error. J. Mark. Res. 1981, 18, 39-50. [CrossRef]

72. Hayes, A.F. Introduction to Mediation, Moderation, and Conditional Process Analysis: A Regression-Based Approach; Guilford Publications: New York, NY, USA, 2017.

73. Ho, S.Y.; Bodoff, D. The effects of Web personalization on user attitude and behavior. MIS Q. 2014, 38, 497-520. [CrossRef]

74. Jiang, Y.; Shang, J.; Liu, Y. Maximizing customer satisfaction through an online recommendation system: A novel associative classification model. Decis. Support Syst. 2010, 48, 470-479. [CrossRef]

75. Berry, L.L.; Zeithaml, V.A.; Parasuraman, A. Five imperatives for improving service quality. MIT Sloan Manag. Rev. 1990, 31, 29.

76. Shin, D. Empathy and embodied experience in virtual environment: To what extent can virtual reality stimulate empathy and embodied experience? Comput. Hum. Behav. 2018, 78, 64-73. [CrossRef]

77. Shin, D.; Biocca, F. Exploring immersive experience in journalism. New Media Soc. 2018, 20, 2800-2823. [CrossRef]

78. Kalajas-Tilga, H.; Hein, V.; Koka, A.; Tilga, H.; Raudsepp, L.; Hagger, M.S. Application of the trans-contextual model to predict change in leisure time physical activity. Psychol. Health 2020, 1-25. [CrossRef]

79. Grubb, E.L.; Stern, B.L. Self-concept and significant others. J. Mark. Res. 1971, 8, 382-385. [CrossRef]

80. Jamal, A.; Goode, M.M. Consumers and brands: A study of the impact of self-image congruence on brand preference and satisfaction. Mark. Intell. Plan. 2001, 19, 482-492. [CrossRef] 